\title{
How Little We Know About Deficit Policy Effects
}

Preston J. Miller

Vice President and

Deputy Director of Research

Federal Reserve Bank of Minneapolis

\author{
William Roberds \\ Research Officer \\ Federal Reserve Bank of Atlanta
}

Do budget deficits matter for the economy in general or real interest rates in particular? About half the available empirical studies say yes, and the other half say no. In this paper, we explain how investigators examining the same body of data can arrive at diametrically opposed conclusions. We show that these studies are flawed by an important statistical problem and that the studies' arbitrary resolution of this problem colors their results. We also argue that this problem is difficult and is not likely to be resolved soon.

The statistical problem is one of identification. It involves determining from reported time series the effects of changes in deficit policies on real economic variables. The problem arises because changes in deficits occur for a variety of reasons, only one of which is changes in policy. Identification requires sorting out the policy contribution to deficits.

The chart on deficits and real interest rates suggests the nature of the identification problem, since it seems to support two very different conclusions. One might conclude from the chart that deficits and real interest rates are unrelated since for certain years they appear positively correlated (early 1950s and 1980s) and for others they appear negatively correlated. On net, the correlation might be close to zero.

The opposite conclusion might be reached, however, if one considers periods longer than years. One then might conclude from the chart that deficit policies are positively related to real interest rates. In the 1960s and 1970s, one policy regime seemed to be in place since little change occurred overall in

The Editorial Board for this paper was Michael P. Keane, Kathleen S. Rolfe, Arthur J. Rolnick, and Richard M. Todd.
Do Budget Deficits Really Matter?

Real Interest Rate on U.S. Treasury Bills* vs. Difference Between Growth in U.S. Federal Debt ${ }^{\dagger}$ and Growth in U.S. GNP

Annually, 1949-87

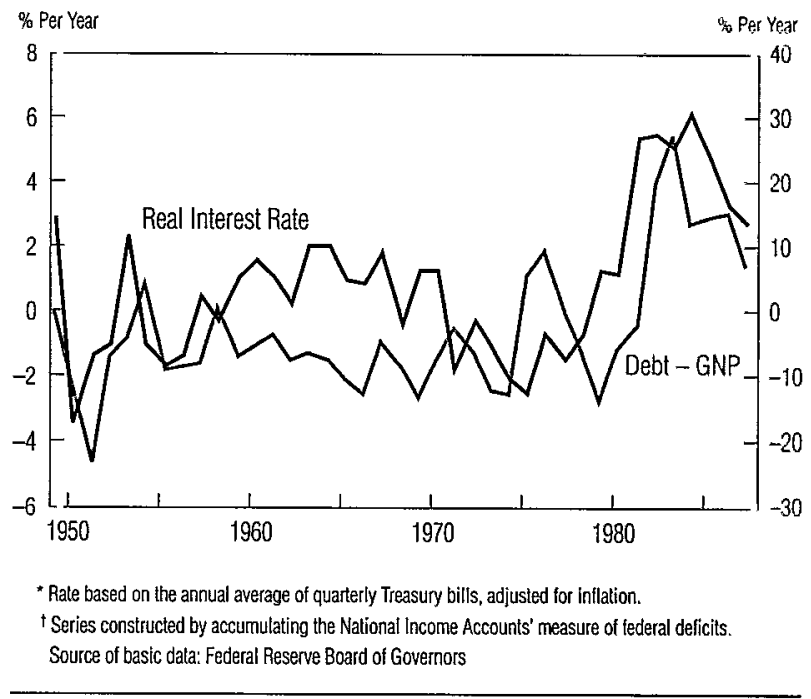

the debt-to-income ratio. Business cycle movements thus could have accounted for the negative correlation between the plotted series over this period. Then in the 1980s, a change in policy leading to a higher debt-to-income ratio could have 
caused a higher real interest rate. What is clear is that the correct interpretation cannot be found by appealing to a graph or to simple correlations. We need instead to examine the problem more deeply.

To do that we make use of an abstract structural model. It is structural in the sense that it is intended to be behavioral; it is abstract in the sense that the relationships are not explicitly derived from individual optimizing behavior. Nevertheless, we maintain that theory suggests aggregate relationships with the arguments we posit. This model is useful in that it subsumes other models used in the literature and allows us to clearly state the identification problem. It is intended to illustrate the nature of the statistical problem without taking a position on deficit theories.

In order to clearly illustrate the identification problem within both its theoretical and empirical guises, we consider a simple form of our abstract structural model. The simple form contains just budget deficits and real interest rates. When we estimate regression equations for this simple form, we find that budget deficits do not help explain real interest rates. But we then show why this regression result is still consistent with a change in deficit policies affecting real interest rates to an arbitrary degree.

After illustrating the identification problem, we survey studies in the literature which have attempted to solve it. Even though these studies represent only a small sample of the literature, they do represent the three main approaches researchers have taken. ${ }^{1}$ With reference to our abstract structural model, we show why these studies have not satisfactorily resolved the identification problem.

\section{Positing an Abstract Structural Model}

We posit our model based on both statistical and theoretical considerations. We discuss these considerations in turn.

\section{Statistical Considerations}

Although budget deficits are often taken as shorthand for policy, they respond to shocks from a variety of sources. The change in an economic variable (such as a real interest rate) which accompanies a change in the observed deficit, can be expected to depend on the source of change in the deficit. A model of budget deficits needs to distinguish among at least three sources of deficit changes.

Budget deficits can change when the state of the economy changes. The degree of sensitivity is suggested by the Congressional Budget Office's (CBO's) rules of thumb, which estimate how much the deficit would change when the levels of output, prices, or interest rates change-all else held equal. (See CBO 1992.) A decline in output caused by a decline in aggregate demand, for example, generally leads to a fall in real interest rates. In this case, lower interest rates would be accompanied by a rise in budget deficits as income tax revenues fall. ${ }^{2}$

The CBO's rules of thumb suggest that the deficit is quite sensitive to changes in the real economy and interest rates but not to changes in inflation. For instance, a one percentage point decline in real growth beginning in January 1992 and continuing indefinitely is estimated to increase the fiscal 1994 budget deficit by $\$ 48$ billion. Similarly, a one percentage point increase in interest rates beginning in January 1992 is estimated to increase the fiscal 1994 budget deficit by $\$ 24$ billion. However, a one percentage point decline in inflation is expected to raise the 1994 budget deficit by only $\$ 4$ billion. The deficit is more sensitive to interest rate changes now than it was in the past because the stock of public debt has roughly quadrupled since 1980 . The deficit is much less sensitive to inflation changes now than it was in the past because of the indexing of income taxes and entitlements begun in 1982.

Budget deficits can also change due to policy shocks under a given policy rule. A policy rule states how taxes and expenditures are set based on current and past states of the economy. But policymakers respond to information and events which economists do not generally include as part of an economic state. For instance, policymakers might increase military spending temporarily to thwart a perceived foreign threat, or they might allow passage of one-time tax breaks as inducements to pass key legislation. One would expect the effect on the real interest rate of such short-term, unpredictable actions to be slight.

Finally, budget deficits can change when the budget policy rule changes. For example, over much of the postwar period, the budget tended to be balanced over the business cycle. This rule seemed to change to one of permanent deficits when the Reagan administration took office. According to some theories, policy rule changes of this type could result in higher real interest rates.

\section{Theoretical Considerations}

This statistical distinction among sources of deficit changes is important because the theoretical issue about deficit effects concerns only effects from changes in policy rules, not shocks or changes in the economy. ${ }^{3}$ That is, different deficits theories make different predictions about the effects of rule changes. More specifically, the two dynamic theories used to analyze

\footnotetext{
IFor an extensive survey of the empirical effects of budget deficits on interest rates, see Congressional Budget Office (CBO) 1987, chap. III. Not surprisingly, reported estimates vary widely.

${ }^{2}$ The relationship of interest rates and deficits when the path of output changes might also depend on the source of output change. A preference shock might suggest one relationship, while a technology shock might suggest another.

${ }^{3}$ Lucas (1976) makes a convincing argument that policy evaluation can only be carried out with respect to rules.
} 
budget policy are the representative-agent, Ricardian model (as in Barro 1974) and the overlapping-generation, nonRicardian model (as in Wallace 1984). Since both theories are dynamic, policy in them must be considered as a function that determines the values of policy variables at any given time conditional on then available information. A rule such as this is a solution to the government's optimization problem, and it is what individuals need to know to solve their expected utility-maximization problems.

The two theories can imply differences in effects of deficit policies on real variables, such as real interest rates. One basic difference concerns the neutrality of inflation. According to either theory, seigniorage, or the inflation tax earned by creating money, is a potential source of revenue to the government. Also, according to either theory, the budget must be balanced in a present value sense when seigniorage is included. Given a path of spending, the government can choose among alternative mixes of the inflation tax and explicit taxes. At issue is whether a change in this mix has real effects.

For Ricardian theories, changing the mixture of inflation and explicit taxes, like changing the time distribution of a given distorting tax, is assumed to have essentially no real effects. Barro (1989, p. 51) states that

The Ricardian approach to budget deficits amounts to the statement that the government's fiscal impact is summarized by the present value of its expenditures. Given this present value, rearrangements of the timing of taxes-as implied by budget deficits-have no first-order effect on the economy. Second-order effects arise for various reasons, which include the distorting effects of taxes. . . .

For non-Ricardian theories, a change in the mix of inflation and explicit taxes is nonneutral. For example, Miller and Wallace (1985) show that such a change corresponds to a different path of the government debt-to-output ratio. In nonRicardian models, a change in deficit financing policies which results in a higher debt-to-output ratio can be associated with a higher real interest rate. ${ }^{4}$

Whether deficits matter, then, involves determining which of these two theories is best supported by the data. More specifically, the question is whether, and if so by how much, real economic processes change when the deficit policy rule changes.

Our Model

Based on the above considerations, we posit our abstract structural model. Those considerations suggest that the policy rule will take a form like

$$
\begin{aligned}
& D_{t}=\alpha+\beta(L) D_{t-1}+\xi X_{t}+\delta(L) X_{t-1}+\theta_{t} \\
& E\left(\theta_{t}\right)=0, \quad \theta_{t} \perp I_{t-1}^{*}
\end{aligned}
$$

where $D_{t}$ is a measure of the budget deficit, $X_{t}$ is a vector of variables which represent the state of the economy, $\beta$ and $\delta$ are polynomials in the lag operator, with $\beta(L)=\beta_{0}+\beta_{1} L+$ ..., and $\delta(L)=\delta_{0}+\delta_{1} L+\ldots$, and the information set $I_{t-1}^{*} \equiv X_{t}$ $\cup I_{t-1}$, and $I_{t-1} \equiv\left\{D_{t-1}, X_{t-1}, D_{t-2}, X_{t-2}, \ldots\right\}$. Because the deficit is affected by the current state of the economy, we explicitly allow for this dependence with the argument $X_{t}{ }^{5}$ This simple rule allows for the three sources of budget deficit changes we established earlier: a change in the state of the economy $\left(X_{t}\right.$, $\left.X_{t-1}\right)$, a policy shock under a given rule $\left(\theta_{t}\right)$, and a change in the policy rule $(\alpha, \beta, \xi$, or $\delta)$.

Our discussion of theory suggests the economic process might take this form:

$$
\begin{aligned}
& X_{t}=\rho+\sigma(L) D_{t-1}+\tau\left(L^{-1}\right) E_{t-1} D_{t}+v(L) X_{t-1}+\psi_{t} \\
& E_{t-1}\left(\psi_{t}\right)=E_{t-1}\left(\theta_{t} \psi_{t}\right)=0, \quad \psi_{t} \perp I_{t-1} \\
& \begin{array}{l}
\begin{aligned}
\tau\left(L^{-1}\right) E_{t-1} D_{t} \equiv & \tau_{0} E_{t-1} D_{t}+\tau_{t} E_{t-1} D_{t+1}+\ldots \\
& +\tau_{n} E_{t-1} D_{t+n}+\ldots
\end{aligned} \\
E_{t-1} D_{t+i} \equiv E\left(D_{t+i} \mid I_{t-1}\right) .
\end{array}
\end{aligned}
$$$$
\text { where }
$$

In the economic process we include real variables, such as a real interest rate. We imagine that the economic process aggregates individual decision rules, giving rise to the $E_{t-1} D_{t+i}$ terms from individuals' dynamic optimization problems. We also imagine that the economic process incorporates marketclearing conditions. Based on Ricardian theories, the economic process for real variables would thus be invariant to any path of the deficit which, together with seigniorage, satisfies present-value balance. This follows because such theories hold that markets will clear with the same real quantities and prices but with changes in private saving offsetting any changes in deficits. According to Ricardian theory, since the invariance must hold for any path of deficits and seigniorage satisfying present-value balance, the $\tau$ coefficients associated

\footnotetext{
${ }^{4}$ In these non-Ricardian models, a higher government debt-to-output ratio is associated with a lower capital-to-output ratio. If the production technology is strictly convex, the latter implies a higher real interest rate (for example, Miller 1983). Other non-Ricardian models exist, however, in which policies are nonneutral, but in which the real interest rate in equilibrium is totally determined by technology or by individuals' constant rate of time preference. Because nonneutral policy changes need not affect the real interest rate, a finding of no relationship between the real interest rate and budget deficit policies does not lead to rejection of non-Ricardian theories. However, a finding of a relationship does lead to rejection of Ricardian theories. Our point in this paper, though, is not to argue whether that relationship is there or not; it is to argue that no one has determined what that relationship is.

${ }^{5}$ Our formulation assumes that all contemporaneous causality runs from $X$ to $D$. This assumption is both plausible and convenient for our purposes, since it reduces the number of parameters in equations (1)-(2) by one. The ensuing analysis, however, is robust to relaxation of this assumption.
} 
with real variables $X$ must be zero. Non-Ricardian theories, in contrast, do not imply invariance to changes in the path of the deficit and thus do not imply $\tau$ is zero. Based on some nonRicardian theories, for example, it follows that for the $\tau^{i}$ 's associated with the real interest rate $X^{i}, \Sigma_{n} \tau_{n}^{i}>0$, since an addition of one unit to the deficit each period would raise the real interest rate. ${ }^{6}$

\section{Identifying the Problem}

Our model is not directly estimable because it includes the expectations terms $E_{t-1} D_{t+i}$. We can, however, estimate a plausible reduced form for $\left(D_{t}, X_{t}\right)$, which is just the unrestricted vector autoregression (VAR) system ${ }^{7}$

$$
\begin{aligned}
& D_{t}=a+b(L) D_{t-1}+c(L) X_{t-1}+u_{t} \\
& X_{t}=d+e(L) D_{t-1}+f(L) X_{t-1}+v_{t}
\end{aligned}
$$

where $u_{t}$ and $v_{t}$ are white noise error terms.

In order to determine the effects of a change in deficit policy - a change in the coefficients of equation (1) - on the economic process in (2), we must be able to identify the coefficients in (1)-(2) from the estimated coefficients in (3)-(4). That would enable us to answer questions such as, Does a permanent increase in the deficit $(\Delta \alpha>0)$ increase the real interest rate $\left(d X^{i} / d \alpha>0\right)$ ?

It is clear, though, that the coefficients of (1)-(2) cannot in general be identified from the estimated coefficients of (3)(4). There are more coefficients in (1)-(2) than there are restrictions in (3)-(4). For arbitrary values of $\tau$, values can be found for the other coefficients of (2), so that the model (1)-(2) generates the model (3)-(4).

We can clearly illustrate the nature of the identification problem and show how it arises in practice by taking the special case where all lag polynomials and $X$ are expressed in terms of real variables instead of vectors. Suppose the abstract structural model has the special form

$$
\begin{aligned}
& D_{t}=\alpha+\beta D_{t-1}+\xi X_{t}+\delta X_{t-1}+\theta_{t} \\
& X_{t}=\rho+\sigma D_{t-1}+\tau E_{t-1} D_{t}+v X_{t-1}+\psi_{t}
\end{aligned}
$$

with

$$
E_{t} \theta_{t}=E_{t} \psi_{t}=E_{t}\left(\theta_{t} \psi_{t}\right)=0
$$

Assuming $\xi \tau \neq 1$, the model (5)-(6) can be put in estimable form to yield

$$
\begin{aligned}
D t= & {[(\alpha+\xi \rho) /(1-\xi \tau)]+[(\beta+\xi \sigma) /(1-\xi \tau)] D_{t-1} } \\
& +[(\delta+\xi v) /(1-\xi \tau)] X_{t-1}+\left[\theta_{t}+\xi \psi_{t}\right]
\end{aligned}
$$

$$
\begin{aligned}
X_{t}= & {[(\rho+\alpha \tau) /(1-\xi \tau)]+[(\sigma+\beta \tau) /(1-\xi \tau)] D_{t-1} } \\
& +[(\nu+\delta \tau) /(1-\xi \tau)] X_{t-1}+\psi_{t} .
\end{aligned}
$$

Regressions provide the estimated coefficients and residuals to the equations

$$
\begin{aligned}
& D_{t}=\hat{a}+\hat{b} D_{t-1}+\hat{c} X_{t-1}+\hat{u}_{t} \\
& X_{t}=\hat{d}+\hat{e} D_{t-1}+\hat{f} X_{t-1}+\hat{\imath}_{t} .
\end{aligned}
$$

Although the system (9)-(10) provides nine restrictions, the underlying system (5)-(6) has 10 unknown coefficients (counting error variances), suggesting the system is not identified. Since (5) is already a regression equation, its coefficients can be identified from (9)-(10). ${ }^{8}$ Thus the coefficients of the economic process $(6)$ are the ones not identified. The identification of the coefficients of (5) is given simply by

$$
\text { (11) } \begin{aligned}
\xi & =\sum_{t} \hat{u}_{t} \hat{v}_{t} /\left(\sum_{t} \hat{v}_{t}^{2}\right) \\
\alpha & =\hat{a}-\xi \hat{d} \\
\hat{\beta} & =\hat{b}-\xi_{\hat{e}} \\
\text { and } \quad \hat{c} & =\hat{c}-\xi \hat{f} .
\end{aligned}
$$

Given these values, (8) and (10) provide three equations in the four unknown coefficients of the economic process, $\rho, \sigma$, $\tau$, and $v$ :

$$
\begin{aligned}
& \rho=\hat{d}-(\hat{\alpha}+\hat{\xi} \hat{d}) \tau \\
& \sigma=\hat{e}-(\hat{\beta}+\xi \hat{e}) \tau
\end{aligned}
$$

and

$$
v=\hat{f}-(\hat{\delta}+\hat{\xi} \hat{f}) \tau
$$

For any arbitrary value of $\tau$ (as long as $\xi \tau \neq 1$ ), these three equations can be solved for $\rho, \sigma$, and $\nu$. [This same argument about underidentification goes through for any finite order lag lengths for the polynomials in (1)-(2).] Estimating (9) and

\footnotetext{
${ }^{6}$ We can imagine models for which $X$ is the real interest rate and $\tau_{i}=$ $\tau / \Pi_{j=1}^{i}\left(1+X_{i+j-1}\right)$, with $X_{0}=0$. In the next section we show that even with a single expectations coefficient $\tau$, the model is not identified as long as the degree of $\sigma$ is arbitrary.

${ }^{7}$ Conditions under which the model $(1)-(2)$ has a unique reduced form corresponding to (3)-(4) can be derived from Watson 1989. Since these conditions are algebraically complicated for the general case and are not intuitively meaningful, we will assume that such conditions hold without explicitly stating them.

${ }^{8}$ Since the coefficients of (5) can be identified, the CBO's rules of thumb provide no additional restrictions to help identify our system.
} 
(10) then cannot pin down the values of $\sigma$ and $\tau$, which must be done to determine whether deficit policies matter.

\section{Estimating Our Model}

We now apply our simple model to the data to show how this problem comes up in practice. We estimate equations (9) and (10) using annual U.S. data over the period 1949-87. We take $D$ to be the growth in outside federal debt less the growth in nominal gross national product (GNP), and we take $X$ to be the annual average of quarterly ex-post real Treasury bill rates. ${ }^{9}$ Recall that plots of the two series were shown on the chart presented earlier. (See the Appendix for a discussion of our choice of variables.)

We estimate (9) and (10) using ordinary least squares. Standard tests of lag lengths in VARs indicate that a one lag specification is appropriate for this system. Estimated coefficients and summary statistics are shown in the table.

Our estimated model seems to share some properties with other models that purport to show deficits do not matter. The coefficient on our deficit measure in the real interest rate equation is not significant at standard levels of confidence. The $F$ tests indicate that deficits do not help in predicting real interest rates. In fact, the real interest rate appears to be well approximated as a first-order autoregressive process.

Appearances can be deceptive, however. This estimated model is actually consistent with deficits mattering as we have defined them. The change in the real interest rate in response to a change in the intercept of the policy rule $\alpha$ is given in (8) by $d X_{t} / d \alpha=\tau /(1-\xi \tau)$.

Since any value of $\tau$ is consistent with our estimated coefficients, we can ask for what values will $d X_{l} / d \alpha$ be significantly positive-say, $d X_{t} / d \alpha>0.5$. We use our model's estimate of $\xi$ of 0.71 and solve for $\tau$ from the inequality

$$
\left(d X_{t} / d \alpha\right)=\tau /(1-0.71 \tau)>0.5 \leftrightarrow 0.37<\tau<1.41 .
$$

For these values of $\tau$, then, it follows that a change in $\alpha$ which initially raises the growth of debt relative to GNP by one percentage point will raise the real interest rate by at least onehalf of a percentage point. For these values of $\tau$, one could find that past deficits do not help in predicting the real interest rate; yet a change in deficit policy which leads to a permanently higher debt-to-income ratio would raise the real interest rate significantly. In fact as $\tau$ gets close to 1.41 , the effect of

\footnotetext{
${ }^{9}$ Ricardian equivalence holds the path of government spending constant and allows the path of tax revenues to change. In our bivariate system, we cannot distinguish between spending and revenue changes. For our empirical results to be relevant for Ricardian equivalence, we must assume that spending is being held constant.

We also constructed a trivariate model which adds federal expenditures net-of-interest. [See discussion following (14) and (15) above] Although that model allows us to distinguish more precisely between Ricardian and non-Ricardian theories, it is more complicated and in no way alters the identification problem which is the focus of this
} paper.

Model Estimates

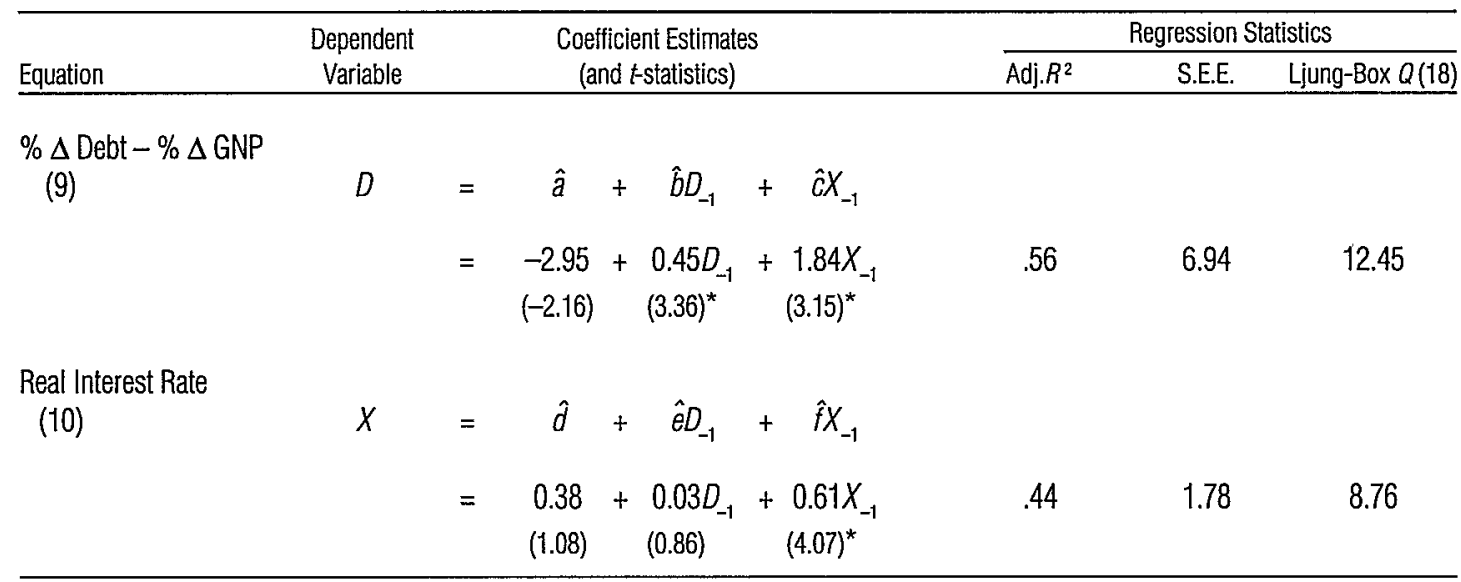

*These $t$-statistics are signilicant at the $95 \%$ confidence level.

Sources of basic data: Federal Reserve Board of Governors, U.S. Department of Comnerce, and U.S. Treasury Department 
higher deficits on the real interest rate becomes arbitrarily large.

\section{Three Approaches That Fail}

Studies in the literature have taken three approaches to quantify the effects of budget policy changes. In this section, we describe these approaches in the context of our abstract structural model and then suggest why these previous studies have not been successful.

\section{Estimating Effects Directly ... .}

One approach is to directly estimate the effects of policy changes as in Miller 1983 and Miller and Roberds 1987. These studies propose dates of policy rule changes, judge whether policy actually changed, and then examine the estimated economic process before and after the potential breaks to check for structural change. The logic is that if the policy rule changes and individuals incorporate the new rule in their expectations, estimated coefficients of a linear econometric process can change. More specifically, in a model such as (1) $-(2)$, a change in $\alpha, \beta, \xi$, or $\delta$ will lead to a change in the estimated coefficients of (4). ${ }^{10}$

This approach is related to Marschak's (1953) method for identifying policy effects. Marschak points out that if enough observations on policy changes exist, one can simply estimate the relationship between the coefficients in (4) and the parameters of (1). From this perspective, the shortcoming of the Miller 1983 and the Miller and Roberds 1987 approach is too few observations to be sure the effects of policy have been identified. This point is illustrated in the following example."

Suppose there are observations on $n$ policy changes at periods $t_{i}=t_{0}+i \Delta t, i=0, \ldots, n-1$, consisting of a change in $\alpha$, where $\alpha_{t_{i}}=\alpha_{0}+i \Delta \alpha, i=0, \ldots, n-1$. We could estimate (4) over each subperiod $\left(t_{i}, t_{i+1}\right)$ and get $n$ estimates of $d, e$, and $f$. The estimated change in the coefficients from one period to the next will in general be different, however, because the $\theta$ 's and $\psi$ 's will be different in each subperiod. With enough observations, the mean of the change in coefficients will go to the true change. With only one policy change, as in Miller 1983 or Miller and Roberds 1987, essentially only one observation is available to estimate the change in coefficients. Thus we have too few observations to determine whether the change in estimated coefficients is due to a change in $\alpha$ or to different draws of $\theta$ and $\psi$ in each subperiod.

... Restricting Coefficients to Zero. . .

A second approach to identifying budget policy effects is to attempt to identify the coefficients of the abstract structural model using restrictions not derived from individual optimizing behavior. That is, if $\tau$ in (2) can be identified, the effects of a change in budget policy can be determined from (4), as in (8). Since $\tau$ cannot be identified from (3) and (4) without some restrictions, the values of $\tau$ found in the literature are as arbitrary as the imposed restrictions. ${ }^{12}$ Arbitrary restrictions cannot solve this identification problem, although most studies in the literature follow this approach.

Dwyer (1982), Evans (1987b), Kormendi (1983), and Plosser (1982) estimate a version of (4) and test whether the coefficients $\hat{e}(L)$ are significant. In effect, these researchers arbitrarily restrict coefficients in (2) to zero. As can be seen in (8), knowing $\hat{e}=0$ by itself only implies that $\sigma$ and $\tau$ are on a particular line. So these studies can be interpreted in one of two ways: either they assume $\sigma=0$ and take $\hat{e}=0$ to imply $\tau=0$, or they assume $\tau=0$ and take $\hat{e}=0$ to imply $\sigma=0$. Either assumption is arbitrary and fails to resolve the identification problem. ${ }^{13}$

Ideally, a test would allow discrimination between Ricardian and non-Ricardian theories. For non-Ricardian theories there is no reason to believe either $\sigma$ or $\tau$ is zero. Restricting either one to zero biases the test results in favor of Ricardian theories. In our estimated model, for example, we found $\hat{e}$ to be insignificantly different from zero, but our finding was shown to be consistent with a structural model in which deficit policies matter significantly.

Some studies using this second method try to estimate $\tau$ directly by using various measures of predicted deficits, the $E_{t-1} D_{t+i}$. If the measures are derived within the model, they are constructed with the aid of incredible identifying assumptions. If the measures are derived outside the model, they are inconsistent with the model's predictions. Either method is unsatisfactory.

Several researchers attempt to construct a series for $E_{t-1} D_{t+i}$ using the predictions of their models. Evans (1987a) assumes that deficits are an exogenous process and tests whether past or future deficits significantly affect interest rates. In terms of our model, Evans (1987a) constructs $E_{t-1} D$, by assuming $\xi=$ $\delta=0$. In the (5)-(6) version of the model, this assumption leads to the estimation equations

$$
D_{t}=a+b D_{t-1}+u_{t}
$$

\footnotetext{
${ }^{10}$ In the case of the estimated model (9) and (10), standard tests of stability suggest that both equations changed during the 1980 s. As discussed below, such results do not necessarily prove that there was a shift in policy during the 1980 s, nor do they prove that higher real rates were caused by such a shift.

${ }^{11}$ This example essentially describes the method used in Poterba and Summers 1987. That study also suffers from too few observations.

${ }^{12}$ Similar arguments were made more generally, or in other contexts, in Sargent 1976 and Sims 1980. We make the argument again since it seems to receive so little attention in the many articles published in the empirical deficit policy literature. A notable exception is Bemheim's 1989 article, which surveys the literature.

${ }^{13}$ Dwyer (1982, p. 327) recognizes this limitation in stating that some of his analysis is "... more tentative because it is based on the adequacy of the structural model which implies the results of the reduced-form tests in this paper."
} 


$$
X_{t}=d+e D_{t-1}+f X_{t-1}+g\left(\hat{a}+\hat{b} D_{t-1}\right)+u_{t}
$$

where $\hat{a}$ and $\hat{b}$ are ordinary least squares estimates of $a$ and $b$.

Two criticisms can be made of Evans' approach. First, the assumption that deficits are exogenous $(\xi=\delta=0)$ is not reasonable. The CBO's rules of thumb suggest they are not exogenous. Our simple annual model implies values of $\xi=0.71$ and $\delta=1.40$. An $F$-test of the nuil hypothesis $H_{0}$, that $\xi=0$ and $\delta=0$, rejects exogeneity at the 1 percent level. In larger systems that include other macroeconomic variables, exogeneity of deficits is also easily rejected..$^{14}$ Hence we regard the assumption of exogeneity as unrealistic. Second, given the assumption that deficits are exogenous, only sums of coefficients on $D$ can be estimated, such as $e+\hat{b} g$. The coefficients $e$ and $g$ cannot be estimated separately, and knowing their weighted sum indicates nothing about their individual values.

Thomas and Abderrezak (1988) use their model to generate values for $E_{t-1} D_{t+i}$ under the assumption that $\sigma=0$. The estimate of $e$ together with estimates for $\beta$ and $\xi$ will then provide an estimate of $\tau: \hat{\tau}=\hat{e} /(\hat{\beta}+\hat{e} \xi)$. [See (8).] There is no reason to believe, however, that $\sigma=0$.

Plosser (1987) uses two estimated equations such as (9)-(10) to generate $E_{t-1} D_{t+i}$ and then tests whether the coefficient $g$ is significant in the augmented equation (10):

$$
X_{t}+d+e D_{t-1}+f X_{t-1}+g E_{t-1} D_{t}+v_{t}
$$

But the calculated series $E_{t-1} D_{t}$ is a linear function of $D_{t-1}$ and $X_{t-1}$. So by construction, adding $E_{t-1} D_{t}$ cannot improve the fit of the equation.

Some others who use this second approach take $E_{t-1} D_{t+i}$ from outside the model (for example, Evans 1987a, Feldstein 1986 , and Plosser 1987). Their measures for $E_{t-1} D_{t+i}$ implicitly incorporate a path for $E_{t} X_{t+i}$ since predictions of deficits generally depend upon an assumed path for the economy. If the $E_{t-1} D_{t+i}, E_{t-1} X_{t+i}$ paths from outside the model match those generated by the model, then those paths are spanned by past $D$ and $X$, and individual coefficients on past and future $D \mathrm{~s}$ cannot be identified as was the case when these paths were generated from within the models. However, in general the paths generated from within the model will be different from those assumed from outside the model. This difference implies an inconsistency: either the model is misspecified, or the values assumed for $E_{t-1} D_{t+i}$ and $E_{t-1} X_{t+i}$ are not individuals' expectations. ${ }^{15}$

\section{... And Estimating Deep Parameters}

Using structural methods is a third approach some studies in the literature take to identify policy effects. The idea is to specify a general equilibrium model and estimate deep param- eters of utility functions. Then the estimated model will determine whether $\sigma$ and $\tau$ are significantly different from zero. (See, for example, Aschauer 1985.)

The problem with this approach is that the result is largely determined by assumptions about interactions among individual agents in the model. For example, if the model assumes all individuals are linked to one another through bequests, then it follows that the model's population can be thought of as a single, infinitely lived, representative agent, and Ricardian equivalence will hold. If instead individuals are not linked through bequests, then deficits that imply shifts in tax burdens across generations will matter. The result depends on how individuals are linked, and that, in turn, depends on more than just the deep parameters of individual utility functions.

Thus we need a grand model in which the linkages among agents can be parameterized and estimated. So far, no one has done that satisfactorily. Using the simplest of settings, Abel and Bernheim (1991) show theoretically how this approach could be followed. Their models are much too simple, however, to attempt to match them to data.

Evans (1991) considers general equilibrium models in which a parameter measures how closely individuals are linked. He shows that for reasonable values of these parameters Ricardian equivalence is a good approximation. While his approach is reasonable, his grand models are not broad enough to span the alternative formulations. Auerbach and Kotlikoff (1987) and Miller and Todd (1991), for example, are able to match to Evans' data nonbequest general equilibrium models for which Ricardian equivalence is a bad approximation.

\section{Concluding Remarks}

Deficit policies may matter, and then again they may not. Existing studies really don't tell us much about their effects because these studies are flawed by the identification problem we have examined here.

Perhaps the most promising approach to alleviate this problem is that taken by Bernheim and Bagwell (1988) and Abel and Bernheim (1991). They show, within given models, under what conditions Ricardian equivalence holds. They then derive in these models other testable implications that follow from those conditions. If the implications are rejected, Ricardian equivalence is also rejected for these models.

The task for future researchers is to construct models of this type that can be matched to the data. Until then, we will

\footnotetext{
${ }^{14}$ See, for example, Dwyer 1982 . We also rejected the exogeneity of deficits in our trivariate system. (See fn 9.)

${ }^{15}$ It could be, for instance, that $E_{t-1} D_{t+i}$ incorporates announced changes about policy, such as a change in $\alpha, \beta, \xi$, or $\delta$. However, ( 9 ) and (10) (augmented or not) assume no change in policy.
} 
have to be content just to clearly understand how little we really know about deficit policy effects.

\section{Appendix Choosing Our Regression Model Variables}

This Appendix explains the choice of regression model variables in the preceding paper. Although our choice of deficit measure is motivated by our theoretical discussion, it is somewhat limited by the constraints of a bivariate system. Not only is our measure affected by budget policy, it also changes due to inflation surprises and to forces that alter the economy's real interest rate or real growth rate. Some of those forces include changes in tastes, technological shocks, or perhaps changes in monetary policy.

We can simply illustrate the relationship between budget policy and our measure using the derivation

$$
D_{t}=\left(\pi_{t}^{e}-\pi_{t}\right)+\left(X_{t}-g_{t}\right)+\left(D E F_{t} / B_{t-1}\right)
$$

where $D$ is our measure of budget policy:

$$
D_{t} \equiv\left(B_{t} / B_{t-1}\right)-\left(Y_{t} / Y_{t-1}\right),
$$

in which

$$
\begin{aligned}
& B=\text { end-of-period outside government debt } \\
& Y=\text { nominal GNP }
\end{aligned}
$$

and where

$$
\begin{aligned}
\pi^{e} & =\text { expected inflation } \\
\pi & =\text { actual inflation } \\
X & =\text { the one-period real interest rate } \\
g & =\text { the growth rate of real GNP } \\
D E F & =\text { the government deficit net-of-interest. }
\end{aligned}
$$

We derive the relationship using simple algebra. We have by definition $B_{t}=\left(1+r_{t}\right) B_{t-1}+D E F_{t}$, where $B$ is debt, $D E F$ is the netof-interest deficit, and $r$ is the nominal one-period interest rate. Relative to nominal income $Y_{t}$, we have

$$
\left(B_{t} / Y_{t}\right)=\left(1+r_{t}\right)\left(B_{t-1} / Y_{t-1}\right)\left(Y_{t-1} / Y_{t}\right)+\left(D E F_{t} / Y_{t}\right)
$$

so that

$$
\begin{aligned}
\left(B_{t} / Y_{t}\right)-\left(B_{t-1} / Y_{t-1}\right) & \\
& =\left[\left(1+r_{t}\right)\left(Y_{t-1} / Y_{t}\right)-1\right]\left(B_{t-1} / Y_{t-1}\right)+\left(D E F_{t} / Y_{t}\right)
\end{aligned}
$$


Our measure $D_{t}$ is given by

(A3)

$$
\begin{aligned}
D_{t} & =\left(B_{t} / B_{t-1}\right)-\left(Y_{t} / Y_{t-1}\right)=\left(Y_{t} / B_{t-1}\right)\left[\left(B_{t} / Y_{t}\right)-\left(B_{t-1} / Y_{t-1}\right)\right] \\
& =\left[\left(1+r_{t}\right)\left(Y_{t-1} / Y_{t}\right)-1\right]\left(Y_{t} / Y_{t-1}\right)+\left(D E F_{t} / B_{t-1}\right)
\end{aligned}
$$

Let

$$
\left(Y_{t} / Y_{t-1}\right)=1+g_{t}+\pi_{t}
$$

where $g$ is the real growth rate and $\pi$ is the inflation rate, and let

$$
\text { (A5) } \quad r_{t}=X_{t}+\pi_{t}^{e}
$$

where $X$ is the real interest rate and $\pi^{e}$ is the expected inflation rate.

We then have

$$
\begin{aligned}
D_{t} & =\left(1+X_{t}+\pi_{t}^{e}\right)-\left(1+g_{t}+\pi_{t}\right)+\left(D E F_{t} / B_{t-1}\right) \\
& =\left(\pi_{t}^{e}-\pi_{t}\right)+\left(X_{t}-g_{t}\right)+\left(D E F_{t} / B_{t-1}\right) .
\end{aligned}
$$

We chose $D_{t}$ rather than $D E F_{t} / B_{t-1}$ as our policy measure for two reasons:

- Even though the latter is a purer measure of budget policy, non-Ricardian theories such as Miller and Wallace 1985 suggest that the real interest rate is affected by changes in the mix of monetary and budget policies that lead to changes in the government debt-to-output ratio. Thus changes in $D E F_{t} / B_{t-1}$ would be expected to have no effect on the real interest rate if they were accommodated by monetary policy and resulted in no change to $D_{t}$.

- The basic issue separating Ricardian and non-Ricardian theories seems to be whether a change in the government debt-to-output ratio is perfectly offset by a change in the opposite direction in the private debt-to-output ratio. For Ricardian theories it is perfectly offset, so the real interest rate should not be sensitive to our policy measure. For nonRicardian theories it is not perfectly offset, so the real interest rate should be sensitive to our measure. 


\section{References}

Abel, Andrew B., and Bemheim, B. Douglas. 1991. Fiscal policy with impure intergenerational altuism. Econometrica 59 (November): 1687-711.

Aschauer, David A. 1985. Fiscal policy and aggregate demand. American Economic Review 75 (March); 117-27.

Auerbach. Alan J., and Kotlikoff, Laurence J. 1987. Dynamic fiscal policy. Cambridge, England: Cambridge University Press.

Barro, Robert J. 1974. Are government bonds net wealth? Journal of Political Economy 82 (November/December); 1095-117.

1989. The Ricardian approach to budget deficits. Journal of Economic Perspectives 3 (Spring): 37-54.

Bemheim, B. Douglas. 1989. A neoclassical perspective on budget deficits. Journal of Economic Perspectives 3 (Spring): 55-72.

Bemheim, B. Douglas, and Bagwell, Kyle. 1988. Is everything neutral? Journal of Political Economy 96 (April): 308-38.

Congressional Budget Office (CBO). 1987. The economic and budget outlook: Fiscal years 1988-1992. A report to the Senate and House committees on the budget-Part I, January. Washington, D.C.: U.S. Government Printing Office.

1992. The economic and budget outlook: Fiscal years 1993-1997. A report to the Senate and House committees on the budget, January. Washington, D.C.: U.S. Government Printing Office.

Dwyer, Gerald P., Jr. 1982. Inflation and government deficits. Economic Inquiry 20 (July): 315-29.

Evans, Paul. 1987a. Interest rates and expected future budget deficits in the United States. Journal of Political Economy 95 (February): 34-58.

. 1987b. Do budget deficits raise nominal interest rates? Evidence from six countries. Journal of Monetary Economics 20 (September): 281-300.

1991. Is Ricardian equivalence a good approximation? Economic Inquiry 29 (October): 626-44.

Feldstein, Martin S. 1986. The budget deficit and the dollar. In Macroeconomics Ammual 1986, ed. Stanley Fischer, pp. 355-92. Cambridge, Mass.: MIT Press.

Kormendi, Roger C. 1983. Government debt, govemment spending, and private sector behavior. American Economic Review 73 (December): 994-1010.

Lucas, Robert E, Jr, 1976. Econometric policy evaluation: A critique. In The Phillips curve and labor markets, ed. Karl Brunner and Allan H. Meltzer. Camegie-
Rochester Conference Series on Public Policy 1: 19-46. Amsterdam: NorthHolland Publishing.

Marschak, Jacob. 1953. Economic measurements for policy and prediction. In Studies in econometric mothod, ed. William C. Hood and Tjalling C. Koopmans, pp. 1-26. New York: John Wiley \& Sons.

Miller, Preston J. 1983. Higher deficit policies lead to higher inflation. Federal Reserve Bank of Minneapolis Quarterly Review 7 (Winter): 8-19.

Miller, Preston J., and Roberds, William. 1987. The quantitative significance of the Lucas critique. Research Department Staff Report 109. Federal Reserve Bank of Minneapolis.

Miller, Preston J., and Todd, Richurd M. 1991. Monetary policy transmission when there are nontraded goods. Research Department Working Paper 481. Federal Reserve Bank of Minneapolis.

Miller, Preston J., and Wallace, Neil. 1985. Intemational coordination of macrocconomic policies: A welfare analysis. Fedleral Resene Bunk of Mfinnertpolis Quarterly Review 9 (Spring): 14-32

Plosser, Charles I. 1982. Government financing decisions and asset returns. Journal of Monetary Econontics 9 (May): 325-52.

1987. Fiscal policy and the term structure. Journal of Monetary Economics 20 (September): 343-67.

Poterba, James M., and Summers, Lawrence H. 1987. Finite lifetimes and the effects of budget deficits on national saving. Journul of Monetary Economics 20 (September): 369-91.

Sargent, Thomas J. 1976. The observational equivalence of natural and unnatural rate theories of macroeconomics. Joumal of Political Economy 84 (June): 631-40.

Sims, Christopher A. 1980. Macrocconomics and reality. Econome'ric'a 48 (Jauuary): $1-48$.

Thomas, Lloyd B., Jr., and Abderrezak, Ali. 1988. Anticipated future budget deficits and the term structure of interest rates. Southern Ecomomic Journal 55 (July): $150-61$.

Wallace, Neil. 1984. Some of the choices for nunctary policy. Federal Resenve Bank of Minneapolis Quarterly Review 8 (Winter): 15-24.

Watscn, Mark W. 1989. Recursive solution methols for dynamic linear rational expectations models. Journal of Econometrics 41 (May): 65-89. 
The views expressed herein are those of the authors and not necessarily those of the Federal Reserve Bank of Minneapolis or the Federal Reserve System. 